\title{
O TRÁFICO DE AFRICANOS NA AMAZÔNIA COLONIAL: ABORDAGENS HISTORIOGRÁFICAS
}

\author{
Marley Antonia Silva da SILVA ${ }^{1}$ \\ Professora da Rede Estadual de Ensino do Pará/SEDUC \\ marleyhist@yahoo.com.br
}

Resumo: Neste trabalho, discute-se a percepção da historiografia acerca do tráfico de africanos escravizados para o Grão-Pará e Rio Negro. A partir das produções analisadas ficou evidente em alguns trabalhos que a presença africana foi colocada em segundo plano, por se considerar que a capitania (Grão-Pará) oferecia condições restritivas ao ingresso do cativo negro. Dentre os elementos impeditivos recorrentes nos trabalhos encontra-se, a pobreza dos moradores, abundância de mão-de-obra indígena, a inconsistência dos empreendimentos agrários (ausência de plantation) e a "incapacidade do tráfico". Entretanto, é evidente na cultura local a presença marcante de elementos africanos; daí a necessidade de os estudiosos buscarem justificar os motivos que possibilitaram o ingresso desses na região. A dita indolência do indígena, o conflito entre religiosos e moradores por causa do domínio desses últimos, o debate em torno da legitimidade da escravidão e escravização do indígena, as epidemias, a experiência brasileira, as dificuldades de apresamento, a resistência do gentio, a legislação indígena dentre outros, são motivos que ajudam a explicar e a entender a presença africana na Amazônia Colonial. Em novas abordagens, já se tem claro que não se pode pensar a presença africana na Amazônia Colonial numa perspectiva estritamente econômica, a região tinha e tem especificidades, pensar a escravidão africana na região implica lançar novos olhares sobre a mesma.

1 Graduada em História pela UFPA. Mestra em História Social da Amazônia pela UFPA. Professora da Rede Estadual de Ensino do Estado do Pará. 
Palavras-chave: Tráfico. Escravos. Amazônia Colônia.

Abstract: This paper discusses the perception of historiography about the trafficking of enslaved Africans to the Grand Para and Rio Negro. From the productions analyzed was evident in some studies that the African presence was in second place, on the grounds that the captaincy (Grão-Pará) offered restrictive conditions to the entry of the captive black. Among the recurring elements impeding the work is, the poverty of the inhabitants, abundance of skilled indigenous manpower, the inconsistency of agrarian enterprises (no plantation) and the "inability of trafficking". However, local culture is evident in the strong presence of African elements, hence the need for scholars seeking to justify the reasons that made possible the entry of these in the region. Said the native indolence, the conflict between religious and residents because the domain of the latter, the debate on the legitimacy of slavery and enslavement of indigenous epidemics, the Brazilian experience, the difficulties of boarding, the resistance of the Gentile, the indigenous law among others, are reasons that help to explain and understand the African presence in the Amazon Colonial. New approaches, there is already clear that one can't think the African presence in the Amazon Colonial in a strictly economic perspective, the region and has had specificities, think African slavery in the region implies launching new looks about the same.

Keywords: Trafficking. Slaves. Amazon Colonial.

\section{Introdução}

Os estudos sobre escravidão africana são volumosos na historiografia brasileira. É indubitável a relevância da obra de Gilberto Freyre, publicada em 1933, na qual a escravidão no Brasil foi caracterizada pela brandura entre senhores e escravos. Além disso, a obra sistematiza o que depois será chamado de democracia racial, questão que, aliás, causou

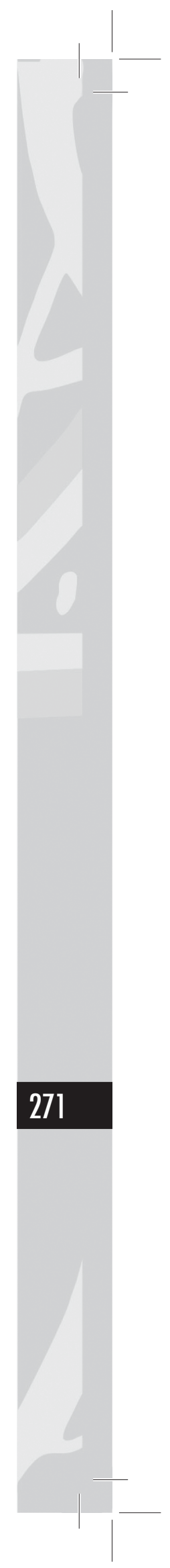




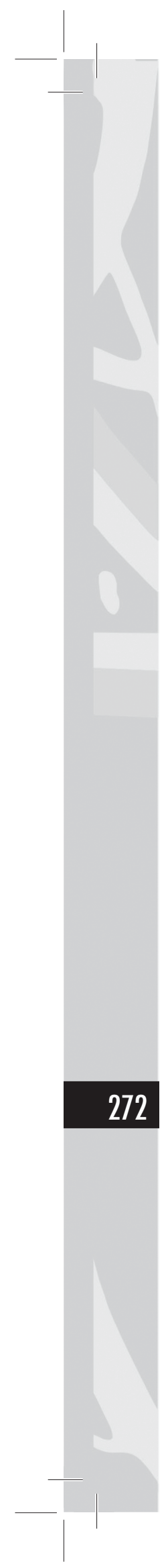

dissenso e contestação nas décadas posteriores ${ }^{2}$. De acordo com Stuart Schwartz (2001, p. 23), o trabalho do sociólogo pernambucano foi um marco na interpretação histórica do Brasil, considerando que foi depois de Casa Grande e Senzala que a escravidão e o negro passaram a ter papel fundamental na narrativa histórica do Brasil.

Entretanto, a escravidão é uma questão ampla que abrange uma série de temas e métodos. No Brasil, as pesquisas sobre tal temática têm avançado e se refinado bastante. O estudo sobre o tráfico de africanos é uma das temáticas sobre a qual têm se debruçado muitos estudiosos, e cada vez mais novos métodos, fontes e teorias têm ampliado o debate sobre o trânsito de homens cativos de África para o Brasil ${ }^{3}$. Cientes de que outros trabalhos já se ocuparam de maneira eficiente do debate historiografia sobre a escravidão e suas muitas dimensões no Brasil, neste espaço nossa atenção se volta para debates historiográficos mais específicos. Nosso intuito nas linhas que seguem é identificar a percepção da historiografia que versa sobre o tráfico de africanos

2 Entre os contestadores mais enfáticos de Freyre, podemos apontar FERNANDES, Florestan. A integração do negro na sociedade de classes. São Paulo: Dominus/Edusp, 1965; IANNI, Otávio. Escravidão e racismo. São Paulo: Hucitec, 1978; VIOTTI DA COSTA, Emília. Da senzala à colônia. São Paulo: Difusão Européia, 1966; CARDOSO, Fernando Henrique. Capitalismo e escravidão no Brasil meridional. São Paulo: Difusão Européia, 1962.

3 Entre os diversos trabalhos destacamos aqui: FLORENTINO, Manolo. Em costas negras: uma história do tráfico de escravos entre a África e o Rio de Janeiro (séculos XVIII e XIX). São Paulo: Companhia das Letras, 1997; ALENCASTRO, Luiz Felipe de. O Trato dos viventes. Formação do Brasil no Atlântico Sul. São Paulo: Companhia das Letras, 2000; RODRIGUES, Jaime. De costa a costa: marinheiros e intermediários do tráfico negreiro de Angola ao Rio de Janeiro (1780-1860). São Paulo: Companhia das Letras, 2005; FERREIRA, Roquinaldo Amaral. Dos sertões ao Atlântico: tráfico ilegal de escravos e comércio lícito em Angola, 1830-1860. Rio de Janeiro: Dissertação de Mestrado, UFRJ, 1996; ASSIS, Marcelo Ferreira de. Tráfico atlântico, impacto microbiano e mortalidade escrava, Rio de Janeiro, c. 1790-c. 1830. Rio de Janeiro: Dissertação de Mestrado, UFRJ, 2002. 
para a Amazônia colonial, privilegiando notadamente aquela que se refere ao Estado do Pará.

Contudo, o debate historiográfico que iremos estabelecer segue menos uma sequência cronológica e mais uma sequência temática. Na leitura dos trabalhos, observamos e elegemos as questões mais recorrentes e os temas mais relevantes no que diz respeito ao tráfico de mancípios africanos para a região. Sabemos que todo trabalho histórico resguarda as marcas de seu tempo e das questões que a sociedade debate e vivencia enquanto é gestado, daí a necessidade de respeitar a especificidade histórica de cada um.

\section{As dificuldades de acesso à mão de obra africana no Pará: a pobreza dos colonos e o extrativismo}

Os negros constituíram mão-de-obra fundamental no Estado do Brasil. No contexto da Amazônia colonial portuguesa, foram os indígenas a principal força de trabalho necessária para a efetivação do projeto colonizador luso. Contudo, a importância fundamental do indígena como força de trabalho (livre ou cativa) não significou uma exclusão do elemento africano.

Esse último era desejado pelos moradores que muitas vezes viam o cativo africano como aquele capaz de fazer o "Estado prosperar"; o negro esteve presente e junto com o indígena constituiu a mão-de-obra tão necessária para a colonização portuguesa. Entretanto, a historiografia de certo modo minimizou a presença do africano por algum tempo, situação que já foi revista graças a alguns trabalhos que buscaram "recolocar" o negro no cenário amazônico.

Não raro a Amazônia Colonial foi entendida, caracterizada e apresentada como "área periférica" do império português (CARDOSO, 1984). Supostamente o local do fracasso, onde não se conseguiu obter o sucesso alcançado por outras capitanias como Bahia, Pernambuco, Rio de Janeiro. Diferentemente do que aconteceu no Estado do Brasil, a mão-deobra africana foi utilizada com menor intensidade especialmente no Grão-Pará. 
Para Maria Celestino de Almeida, "características peculiares da colonização da Amazônia permitiram que a população indígena fosse utilizada como mão-de-obra predominante por um período mais longo" (1988, p. 105). O gentio constituiu mão-de-obra fundamental para a colonização portuguesa na região, ao ponto de causar sérios conflitos entre religiosos e moradores. Desse modo, foi o natural da terra e não o africano o trabalhador numericamente mais expressivo.

A utilização massiva dos indígenas se explica por ser o extrativismo atividade importante na região e o aborígene ter habilidade para a coleta de produtos na floresta, por isso que de acordo com Vicente Salles (2005, p.30),

[...] houve, porém, desde o início condições bastante desfavoráveis para a introdução do negro escravo: não só os recursos dos colonos eram escassos como o negro mal se adaptaria ao tipo de atividade econômica mais rentável, o extrativismo.

$\mathrm{Na}$ tentativa de caracterizar a força de trabalho na Amazônia, Maria Celestino de Almeida afirma que a maior riqueza da região era justamente a mão-de-obra indígena, argumentando que a agricultura não podia ser desenvolvida de forma satisfatória, já que não havia escravos (africanos) para desenvolver a lavoura. "A terra era abundante, mas a preparação do terreno para a agricultura exigia uma farta escravatura que o escasso capital dos colonos paraenses não permitia adquirir" (1988, p. 30).

Arthur Cezar Ferreira Reis (1961, p. 350), um pioneiro no tema, ressaltou a relevância do negro no aspecto social e salientava para a necessidade da investigação do mesmo na Amazônia, aponta justamente para a questão da pobreza dos moradores que impossibilitava a importação de trabalhadores africanos.

A população era, porém, pobre, muito pobre mesmo. Escasseavam os recursos para a importação do braço africano. E ainda, apesar de todas as 
dificuldades, naturais ou criadas, o contingente gentio local era o suficiente.

A miséria dos colonos fazia com que, mesmo quando adquiriam escravos obtinham os de "má qualidade", ainda por conta de não terem o suficiente para oferecer um preço atrativo aos mercadores, ao menos é o que afirma Pereira, "também, dada à pobreza dos negociantes do Pará, os que se incumbiam de introduzi-los não os podiam pagar por preços mais vantajosos oferecidos por negociantes de outras capitanias" (1949, p. 511).

As denominadas drogas do sertão (cacau, cravo, canela, etc.) constituíam a fonte de riqueza a que os lusitanos se atiravam. Tais matérias-primas exportáveis eram encontradas no interior da floresta, o gentio era quem melhor poderia recolher a mercadoria no interior da vegetação, já que conhecia bem a floresta, e com facilidade fazia a coleta como afirma Reis (1961, p. 349), "Ora, para a identificação das espécies amazônicas que deviam ser colhidas na floresta, o negro africano não era mão-de-obra indicada. Essa devia ser solicitada aos continentes da bugrada local. Daí o descaso pela contribuição africana que não fazia falta”.

Foi justamente "a pobreza da região Amazônica, o antigo Estado do Maranhão e Grão-Pará, que evitou um sistema de escravidão negra tal como caracterizou o Nordeste do Brasil" pontua Sue Gross (1975, p. 211). Como já se notou, o pauperismo dos moradores é apontado pela historiografia, como um fator restritivo, ao ingresso do cativo africano. De qualquer modo o argumento da pobreza é recorrente nos trabalhos e, aliado a outros fatores, como o extrativismo, contribui na explicação da "ausência negra".

Contudo, há uma insistência da historiografia na importância da agricultura, ou melhor, na inexistência da monocultura de exportação (ocorrida especialmente no nordeste açucareiro) como condição para o não desenvolvimento de um sistema de escravidão negra na Amazônia, tal como aconteceu no Estado do Brasil.

Dito de outro modo, o desenvolvimento das plantations esteve intimamente ligado à utilização de maneira abundante da 


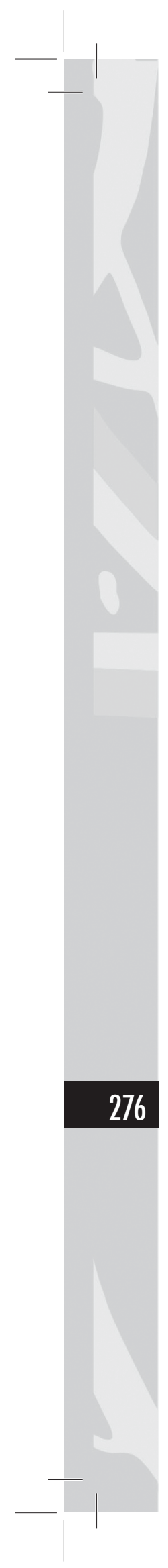

força de trabalho de origem africana. Podemos inferir disso que o gentio era preterido quando se tratava de atividade agrícola, aliás, é exatamente a afirmativa de Salles, que ao abordar o negro diz: "Este viria depois e se destinaria aos trabalhos da lavoura, a fim de substituir a mão-de-obra indígena que escasseava rapidamente e não se adaptava aos rudes labores do campo" (2005, p. 35). O que já não acontecia nas atividades de coleta no interior da floresta.

Nesse sentido, como já apontamos, o extrativismo era uma importante atividade econômica, com a qual o ameríndio se ocupava preferencialmente. Sobre a relevância do extrativismo como atividade econômica da região, Salles enuncia que "o extrativismo, que dava algum lucro, era atividade predatória: dela podia ocupar-se o indígena, senhor da terra". Percebe-se a relação entre extrativismo e utilização da mão-de-obra indígena. "Assim, a Amazônia era uma região que não oferecia um mercado estável ao tráfico negreiro, já que o negro escasso e caro podia ser substituído eficientemente pelo índio" (2005, p. 27, p. 104).

$\mathrm{O}$ tráfico que permitia a entrada do elemento africano na região aparece sempre como uma atividade sem vigor, como uma atividade "incapaz" de promover a entrada de braços africanos, especialmente quando tratamos do século XVII e as primeiras décadas do século XVIII. Nessa direção, Reis (1961, p. 350) menciona que "as entradas eram pouco frequentes. Os navios que vinham ao Pará tampouco eram constantes. A região vivia, a certos aspectos, desligada do mundo, mesmo o mundo português".

Segundo a historiografia, as condições de inserção do africano eram "pouco atrativas" no Grão-Pará, pois não existia um mercado que tivesse condições de absorver trabalhadores africanos, fosse porque sua atividade principal se assentava na mão-de-obra ameríndia ou pelo fato de não haver recursos. Tal situação contribuiu para que houvesse uma "inconsistência do tráfico", evidenciada no trabalho citado acima.

Esse raciocínio contribuiu para que as investigações quantitativas sobre o tráfico no Grão-Pará não se alargassem. Se por um lado afirmou-se que o negro não foi numericamente 
expressivo, não se pôde ignorar sua participação na sociedade em questão. Nesse sentido, houve a necessidade de explicar a presença africana em um local onde a presença do índio foi deveras expressiva.

\subsection{As causas da inserção africana}

Segundo a historiografia, havia um contexto adverso para utilização do africano em larga escala - pobreza dos colonos, extrativismo, abundância da mão-de-obra indígena e a debilidade do tráfico - na Amazônia Colonial, mas os trabalhos não deixaram de apontar a entrada e a contribuição do africano. Os fatores que possibilitaram a introdução dos trabalhadores cativos oriundos da África são diversos e aparecem nos distintos trabalhos.

Dissemos que o indígena era preferido, como força de trabalho na coleta das drogas do sertão, mas quando se tratava da lavoura na Amazônia colonial havia, aparentemente, uma predileção pelo braço africano. Reis (1961, p. 347) argumenta sobre essa questão afirmando que,

No tocante à actividade econômica, nos contactos com o gentio da terra, verificadas certas reacções que faziam ao trabalho sedentário, à mudança de técnicas de vida, o caminho foi a utilização da mão-de-obra africana, mais dócil.

Havia outro empecilho que comprometia a utilização do gentio na lavoura: o indígena era considerado indolente e, além disso, mais hostil ao apresamento. No mesmo sentido, Salles (2005, p. 73), ao retratar o fracasso da lavoura, inclui a mencionada indolência do nativo, como um fator que contribuiu para a "decadência" da lavoura na Amazônia.

A relação entre agricultura e braços negros é uma afirmativa que é apresentada em Reis (1961, p. 347), pois "a utilização da mão-de-obra africana, mais dócil e, seguramente, mais fácil de conseguir, conquanto importasse em despesas que 


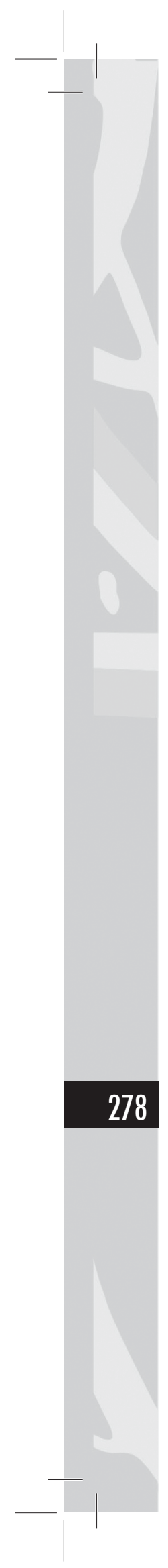

nem sempre compensavam pelo menos no imediatismo de sua utilização pelos colonos".

Em Salles (2005, p. 26-27), a justificativa para a presença de africanos na referida região, ocorreu, dentre outros fatores, do desacordo entre colonos e religiosos (especialmente jesuítas) com relação à mão-de-obra indígena, pois os colonos queriam dominar os indígenas e reduzi-los à escravidão, e os jesuítas também os pretendiam para si. Dessas desavenças derivou a introdução da escravaria de África que, promovida pelos jesuítas, representava um acordo. Como último recurso, aceitava-se o negro escravo que deveria ocupar o lugar do gentio nos trabalhos da lavoura.

Esse conflito, relativo à tutela dos índios, que ocorria entre moradores e religiosos, acabou por incentivar a introdução de africanos nestas paragens; isso acabava por desembocar em outra questão: a da legitimidade da escravidão africana em detrimento da indígena. No universo católico, havia uma espécie de legitimação da escravidão africana, o mesmo não ocorria com relação ao indígena, nesse sentido havia uma aceitação de que escravizar africanos era legítimo, enquanto escravizar índios não.

É que o negro só teria acesso à fé por meio do cativeiro, isso estaria de acordo com os desígnios de Deus e, por tal motivo, não se poderia pôr em questão a legitimidade da escravidão africana; essa era a doutrina do Padre Vieira, e que expressava a concepção da época. Por outro lado, escravizar o ameríndio incorria em causar "ofensas" a Deus. Saraiva (1992, p. 56), ao analisar a questão da legitimidade da escravatura para o Padre Antônio Vieira, ressalta, resumidamente, que a questão "tratavase de substituir, junto dos colonos, os índios libertos que seriam colocados sob a administração dos jesuítas. Os negros para os colonos, os índios para os jesuítas”.

A oposição entre religiosos e os colonos, somados à ilegitimidade da escravização do gentio, importantes é fator importante que nos ajuda a entender, de acordo com a historiografia, os motivos que possibilitaram a atração de cativos africanos para a região, embora a Amazônia oferecesse condições "desfavoráveis" para o ingresso dessa mão-de-obra. 
Com o decorrer do processo de colonização, o número de índios diminuiu gradativamente por conta das guerras e pelos surtos epidêmicos. As epidemias ocorreram nos séculos XVII, XVIII e XIX. Na economia, esse surto de doenças que enfermava e matava muitos índios causava resultados desastrosos, já que indígenas, como vimos, constituíam força de trabalho fundamental para a sociedade.

Para Chambouleyron (2006, p. 81), “o impacto das epidemias de varíola sobre os trabalhadores indígenas ensejou uma 'corrida' aos africanos, principalmente na década de 1690". O resultado das epidemias e das guerras foi a morte de milhares de indígenas, ocasionando uma queda na densidade da população ameríndia. Tal situação era atrativa para a aquisição de cativos africanos já que o contingente local tão requisitado diminuía sensivelmente.

A introdução do cativo africano também se explica por conta da experiência brasileira. O sucesso da lavoura açucareira obtido em algumas capitanias do Brasil fazia com que se acreditasse que a prosperidade alcançada tinha sido obtida graças à utilização do braço africano. Tal perspectiva fica evidente em "inúmeros textos seiscentistas [...], a imagem de que o Estado do Brasil só havia prosperado graças ao uso de africanos tornase um argumento fundamental para defender o urgente envio de escravos da África", nos dizeres de Chambouleyron (2006, p. 80).

É o que também afirma Salles (2005, p. 27), ao ressaltar "a experiência que se realizava no Estado do Brasil, onde o negro substituiu vantajosamente o braço indígena, deve ter estimulado essa resolução ou inspirado seus proponentes". Na mesma direção Maria Celestino de Almeida (1988, p. 103) argumenta que "o modelo ideal da economia de plantation trabalhada pelo escravo negro, introduzido com sucesso no Estado do Brasil, teria motivado as autoridades a tentar introduzi-lo também na Amazônia”.

O estabelecimento da lei de liberdade dos índios de 1755, que buscava transformar os índios em vassalos, e, por outro lado, a criação da empresa monopolista permitiram um incremento do tráfico de mancípios para a região. Na perspectiva de Nádia

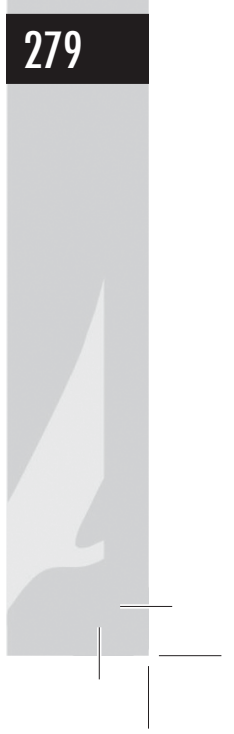


Farage (1991, p. 34), o período pombalino no Grão-Pará foi acompanhado de medidas articuladas,

\section{[...] a formação da Companhia Geral de Comércio do Grão-Pará e Maranhão, para a comercialização da produção amazônica e introdução sistemática de escravos africanos na colônia; o fim da escravidão indígena; e a retirada do poder temporal dos missionários sobre os aldeamentos indígenas, seguida da expulsão dos jesuítas.}

O resultado desta política provocou mudanças significativas no cenário amazônico, no que se refere à inserção de cativos oriundos do continente africano, em certa medida atendeu seus objetivos no Grão-Pará, pois houve um incremento e regularização do tráfico, numa tentativa de suprir a mãode-obra indígena que ao menos teoricamente se encontrava distante do cativeiro.

\subsection{O negro na Amazônia Colonial, novas abordagens}

As investigações no campo da antropologia nas décadas de 1960 e 1970 não se deixaram limitar pelas explicações socioeconômicas que diziam que o tráfico de africanos não teve vigor suficiente para que o negro ocupasse um espaço significativo na sociedade paraense; nesse contexto surgiram estudos voltados para a investigação do negro na região ${ }^{4}$.

4 SALLES, Vicente. “O negro no Pará: sob o regime de escravidão”. Rio, Fundação Getúlio Vargas \& Univ. Fed. do Parti, 1971.336 p.; VERGOLINO e SILVA, Anaiza. "Alguns elementos para o estudo do negro na Amazônia"Belém, Museu Paraense E. Goeldi, 1968. (Publ. Avulsas, 8); “O negro no Pará: uma notícia histórica”. Antologia da Cultura Amazônica. Belém, Amazônia: Ed. Culturais, 1971 (Antropologia e Folclore, v. 6); "O Tambor das Flores; estruturação e simbolismo ritual de uma Festa da Federação Espírita Umbandista e dos Cultos Afro-Brasileiros no Pará"Campinas. Inst. Filosofia e C. Humanas, 
Na década de 1980, o interesse sobre o negro no Pará se intensifica com a comemoração do centenário da abolição da escravidão, que fomenta os debates relacionados ao racismo e à escravidão. Nesse período é reeditado o trabalho de Salles, graças à parceria do Centro de Defesa do Negro no Pará (CEDENPA) com a Secretaria de Estado da Cultura do Pará. São igualmente publicados artigos relacionados ao tema, como "Africanos na Amazônia: cem anos antes da Abolição" de Arlene Marie KellyNormand (1988); outra publicação que deve ser mencionada é a cartilha do CEDENPA (1988).

As pesquisas relacionadas ao tema foram se avolumando e o interesse de Anaíza Vergolino e Napoleão Figueiredo em investigar os cultos afros de Belém, buscando descobrir suas áreas de procedência e as referências de manifestações religiosas mais antigas, não alcançaram seus objetivos iniciais. Entretanto, produziram um trabalho ímpar, pois não se conformaram em analisar a participação do negro unicamente na perspectiva da plantation, apontaram que o tráfico para a região tinha características distintas daquele realizado em outras regiões do Brasil. Além disso, sistematizaram e compilaram a documentação do Arquivo Público do Pará referente ao negro no período colonial.

Os trabalhos voltados para análise dos quilombos/ mocambos também possibilitaram uma maior visibilidade ao negro na região. As publicações de Rosa Acevedo (1988), Edna Castro (2004), Eurípedes Funes (1995) e Flávio Gomes (1997) são valiosas contribuições para o estudo da presença africana na região. Com tantos quilombos, a questão da chegada desses africanos na região tornou-se uma questão pungente.

Com a publicação do livro Escravidão negra no Grão-Pará em 2001, José Maia Bezerra Neto, sensível à questão da escravidão africana na Amazônia e ao aumento dos trabalhos que versavam sobre a temática, sintetizou boa parte dos conhecimentos que haviam sido produzidos sobre a escravidão no Pará; além

1973. (Projeto de Pesquisas para tese de Mestrado em Antropologia Social, Univ. Estadual de Campinas). 


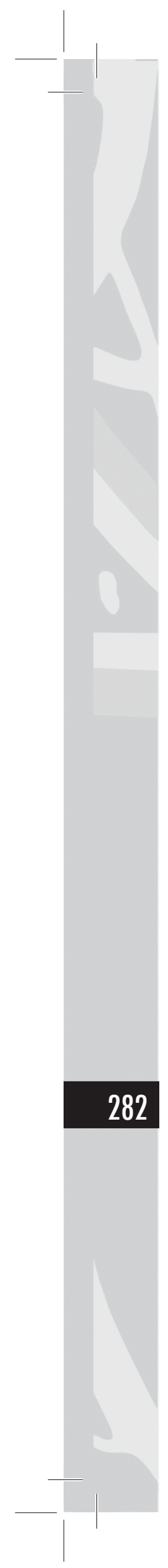

disso, o autor realizou análises e críticas importantes, que serão apontadas nos parágrafos seguintes. Com isso é o historiador que tem capitaneado e alavancado as pesquisas sobre os distintos aspectos da escravidão negra no mencionado Estado.

Os artigos de Rafael Chambouleyron também contribuíram de maneira significativa para a compreensão de aspectos importantes relacionados à escravização de africanos especialmente sobre o tráfico no século XVII e meados do século XVIII. Os trabalhos Suspiros por um escravo de Angola (2004) e Escravos do Atlântico Equatorial (2006) são exemplos de produções com análises importantes sobre o tráfico para um período considerado de relevância secundária para a historiografia. É necessário pontuar que, além das investigações locais, a contribuição de pesquisadores brasileiros e estrangeiros, por meio de artigos, notas e outros trabalhos acadêmicos tem sido crescente. Teremos a oportunidade de mencionar e comentar os principais no decorrer de nossa argumentação.

Ainda que os trabalhos venham se avolumando, de acordo com Patrícia Sampaio (2007, p.2), "usualmente, o tema da escravidão na Amazônia provoca estranhamento porque já se tornou comum afirmar que sua presença foi pouco significativa na economia regional dos séculos XVII e XVIII". Já nos referimos de maneira sintética aos avanços nos trabalhos e publicações sobre o tema, vamos agora nos deter sobre os principais argumentos das novas abordagens.

Esse "estranhamento" ao qual se referiu Patrícia Sampaio foi construído nos clássicos da história econômica, que criaram uma dicotomia entre atividade extrativa versus plantation como aponta Chambouleyron (2007, p. 4):

A historiografia insistiu nesta contradição para entender a economia amazônica. Em vários trabalhos como os escritos por Caio Prado Júnior, Celso Furtado, Roberto Simonsen, Nelson Werneck Sodré e Arthur Cezar Ferreira Reis, a economia [...] foi pensada comparativamente a outras experiências coloniais - notadamente o Nordeste açucareiro - 
revelando o fracasso da implementação de uma economia baseada na escravidão africana e no desenvolvimento de plantation.

No modelo estabelecido pelos trabalhos de história econômica, há sim uma ausência de africanos; essa leitura cristalizou-se e por tal motivo não parece "normal" vislumbrar esse sujeito no cenário da Amazônia Colonial. Como bem colocou Vergolino (1990, p. 31), "o número de negros escravos entrados na Amazônia colonial foi bem menor que aquele introduzido no Nordeste, contudo, a questão que se coloca não é a de inverter as cifras do tráfico. Trata-se, isto sim, de se duvidar do vazio humano".

Alguns pesquisadores não acataram uma explicação que entende a Amazônia Colonial como área periférica ou local do insucesso, o que os permitiu avançar para outros meandros da presença africana na Amazônia. Nesse sentido, os trabalhos buscaram perceber a sociedade que investigavam não naquilo em que ela se assemelhava às demais regiões; em vez disso, apuraram o olhar para perceber que a Amazônia colonial tinha suas peculiaridades e sua lógica própria.

Nessa perspectiva, Bezerra Neto (2001, p. 18) destacou que "não se deve buscar nas experiências das sociedades coloniais existentes em parte do mundo colonial lusitano a compreensão para o tipo de sociedade colonial surgida na região Amazônia”. Para dar sustentação a seu argumento, o autor evidencia que, no cenário em questão, houve o imbricamento das relações sociais envolvendo o estabelecimento do extrativismo das drogas do sertão, o apresamento de índios e a existência de uma agropecuária voltada para o mercado, com a consequente utilização do trabalho escravo africano. Essa ligação estreita entre tais elementos constituía um de seus pilares; é por isso que na perspectiva do mesmo, deve-se evitar a leitura da Amazônia como área periférica da América Colonial Portuguesa. No que diz respeito ao extrativismo é importante salientar que o mesmo não significou uma exclusão de outras atividades econômicas, antes houve a coexistência do extrativismo com outras atividades, 
como a agricultura e atividades criatórias. Para Bezerra Neto (2001, p. 17),

[...] o processo de colonização lusa na Amazônia implicou igualmente no estabelecimento de uma economia e sociedade lastreadas em atividades agrícolas e criatórias voltadas para o mercado, explorando igualmente o trabalho cativo dos índios e, sobretudo, o trabalho escravo de origem africana".

Essa ideia de que extrativismo, agricultura e atividades criatórias não se excluíam é relevante, pois essa leitura algumas vezes impediu que fossem notadas as especificidades da sociedade a qual nos referimos. Como defende José Maia Bezerra Neto (2001, p. 17),

[...] é preciso também perceber as especificidades do mundo colonial português existente na região amazônica, por si mesmo distante, distinto $e$ diferenciado do restante da América Portuguesa, seja o Nordeste ou o Centro-Sul.

Nesse sentido, podemos pensar com um maior cuidado, a particularidade da região ao invés de compararmos realidades distintas, como já evidenciamos. Outro equívoco que deve ser repensado é o de que as mãos-de-obra indígena e africana se excluía, pelo contrário, elas coexistiam, como já evidenciou Chambouleyron (2004,p.105-106), "escravos africanos e trabalhadores indígenas (livres ou escravos) não eram pensados de forma incompatível".

Se por um lado os colonos eram desejosos de adquirir o indígena para realizar as mais diversas funções; por outro, queriam o negro para realizar inúmeras atividades, especialmente o trabalho na agricultura. Não era demais solicitar mão-de-obra distinta para uma sociedade que se dizia carente de braços para o trabalho.

O tráfico incipiente é outra questão que foi redimensionada, pois, se numericamente não fora tão expressivo como para Bahia e 
Rio de Janeiro, foi/é preciso avançar para perceber as motivações que fizeram com que tal comércio fosse distinto. Nessa direção, Chambouleyron (2004, p. 81) aponta que "o tráfico negreiro ao longo do século XVII e início do século XVIII se organizou a partir de pressupostos diferentes do tráfico brasileiro". O autor chama atenção para o fato de que o tráfico para o Maranhão e Grão-Pará era organizado a partir da Coroa, diferentemente de outras praças como Bahia, Pernambuco ou Rio de Janeiro.

Nas capitanias do Grão-Pará e Maranhão (século XVII e meados do XVIII), ainda na perspectiva de Chambouleyron, o tráfico se organiza em razão de elementos outros como as epidemias, as leis de liberdade indígena e os interesses da Fazenda Real na região. É válido também lembrar que as políticas formuladas pela coroa tinham relação com as especificidades locais já que o governo da Amazônia Portuguesa permaneceu separado do governo do Estado do Brasil por quase duzentos anos. Nesse sentido, o tráfico era distinto, como era distinta a realidade amazônica.

\section{Conclusão}

A historiografia da década de 1970 e até meados da década de 1980, baseada nos argumentos de pobreza dos moradores, no extrativismo e na facilidade de acesso a farta mão de obra indígena, em certa medida minimizou a presença africana no Pará, entretanto os debates acalorados durante as comemorações do centenário da abolição contribuíram para alterar esse quadro e vem ocorrendo uma sensível modificação, na perspectiva que se tinha sobre o negro, pois as pesquisas e o interesse dos estudiosos sobre a região vêm se ampliando.

Parte considerável dos devedores e opositores da empresa mercantil desejava a extinção do monopólio e o conseguiu em 5 de janeiro de 1778. Aqueles que antes reclamavam da ação da empresa monopolista, no período posterior continuavam reclamando das dificuldades em obter trabalhadores oriundos da África, inclusive havia um saudosismo dos tempos em que a Companhia de Comércio fornecia cativos a prazo. 
No que diz respeito aos aspectos numéricos, após o fim do monopólio a metrópole buscou estimular o comércio de almas, em direção ao Grão-Pará e Rio Negro; isso ocorreu especialmente por meio da isenção de impostos. Tais isenções foram especialmente direcionadas para o reino de Angola, ainda que tenha incluído outros portos como do Estado do Brasil como Rio de Janeiro, Bahia e Pernambuco. O redirecionamento dessa e comércio para o Atlântico Sul é curioso, porque ocorre 21 anos antes do Tratado de 1815, que proibia esse comércio ao norte do equador, de onde comumente vinha a maior parte dos cativos africanos para a Amazônia Colonial.

\section{REFERÊNCIAS}

ACEVEDO MARIN, Rosa Elizabeth. Agricultura no delta d rio amazonas:colonos produtores de alimentos em Macapá no período colonial. In: A escrita da história paraense. Belém: NAEA/ UFPa, 1998.

ACEVEDO, Rosa; CASTRO, Edna. Negros do Trombeta: Guardiões dos matos e rios,. Belém: NAEA/UFPA, 1998.

ALENCASTRO, Luiz Felipe de. O Trato dos viventes. Formação do Brasil no Atlântico Sul. São Paulo: Companhia das Letras, 2000.

ALMEIDA, Maria Celestino de. Trabalho compulsório na Amazônia: séculos XVII-XVIII. Revista Arrabaldes, ano I, n. 2, set.-dez. 1988).

ASSIS, Marcelo Ferreira de. Tráfico atlântico, impacto microbiano e mortalidade escrava. Rio de Janeiro, c. 1790-c. 1830. 2002. Dissertação de Mestrado. UFRJ, Rio de Janeiro, 2002.

BEZERRA NETO, José Maia. Escravidão negra no Grão-Pará: sécs. XVII-XIX. Belém: Paka-Tatu, 2001. 
CARDOSO, Ciro Flamarion. Economia e Sociedade em áreas coloniais periféricas: Guiana Francesa e Grão-Pará 1750 e 1817. Rio de Janeiro: Editora Graal, 1984.

CARDOSO, Fernando Henrique. Capitalismo e escravidão no Brasil meridional. São Paulo: Difusão Européia, 1962.

CARTILHA DO CEDEMPA. Raça Negra: A luta pela liberdade. Belém, 1988.

CHAMBOULEYRON, Rafael. Suspiros por um escravo de Angola. Discursos sobre a mão- de-obra africana na Amazônia seiscentista. Humânitas, Belém, v. 20, n. 1/2, pp. 141-63 2004.

CHAMBOULEYRON, Rafael. Escravos do Atlântico equatorial: tráfico negreiro para o estado do Maranhão e Pará (séculos XVII e início do XVIII). Revista Brasileira de História, v. 26, n. 52, 2006.

CHAMBOUlEYRON, Rafael. O governo dos sertões. Açúcar, aguardente e índios na Amazônia Colonial. Texto apresentado no Seminário de Estudos Coloniais/UFPA, outubro de 2007.

FARAGE, Nádia. As muralhas dos sertões: os povos indígenas no rio branco e a colonização. Rio de Janeiro: Paz e Terra, 1991.

FERNANDES, Florestan. A integração do negro na sociedade de classes. São Paulo: Dominus/Edusp, 1965.

FERREIRA, Roquinaldo Amaral. Dos sertões ao Atlântico: tráfico ilegal de escravos e comércio lícito em Angola, 1830-1860. . Dissertação de Mestrado. UFRJ, Rio de Janeiro, 1996.

FLORENTINO, Manolo. Em costas negras: uma história do tráfico de escravos entre a África e o Rio de Janeiro (séculos XVIII e XIX). São Paulo: Companhia das Letras, 1997. 
GROSS, Sue Anderson. Labor in Amazonia in first half of the eighteenth century. The Americas, v. XXXII, n. 2, pp. 211-21, out. 1975.

GOMES, Flávio dos Santos. A Hidra e os Pântanos: quilombos e mocambos no Brasil (sécs. XVII-XIX). Campinas-SP, 1997.

KELLY-NORMAND, Arlene Marie. Africanos na Amazônia cem anos antes da abolição. Cadernos do CFCH, Belém, v. 18, out.-dez. 1988.

IANNI, Otávio. Escravidão e Racismo. São Paulo: Hucitec, 1978.

PEREIRA, Manuel Nunes. A introdução do negro na Amazônia. Boletim Geográfico - IBGE, v. 7, n. 77, pp. 509-15, 1949.

PEREIRA, Manuel Nunes. Negros escravos na Amazônia. In: X CONGRESSO BRASILEIRO DE GEOGRAFIA. Anais. Rio de Janeiro: Conselho Nacional de Geografia, v. 3, pp. 153-85, 1952.

REIS, Arthur Cezar Ferreira. O negro na empresa colonial dos portugueses na Amazônia. In: CONGRESSO INTERNACIONAL DE HISTÓRIA DOS DESCOBRIMENTOS. Actas. Lisboa: Comissão Executiva das Comemorações da Morte do Infante Dom Henrique, v. V, II parte, pp. 347-53, 1961.

RODRIGUES, Jaime. Decosta a costa: marinheiros eintermediários do tráfico negreiro de Angola ao Rio de Janeiro (1780-1860). São Paulo: Companhia das Letras, 2005.

SAMPAIO, Patrícia Melo. Escravidão e Liberdade na Amazônia: notas de pesquisa sobre o mundo do trabalho indígena e africano. In: $3^{\circ}$ ENCONTRO DE ESCRAVIDÃO E LIBERDADE NO BRASIL MERIDIONAL. Florianópolis, 2007. Disponível em: http://www. labhstc.ufsc.br/pdf2007/53.53.pdf. Acesso em: 18 jan. 2008.

- "Administração colonial e legislação indigenista na Amazônia portuguesa”. In: PRIORE, M. del \& GOMES, F. dos 